\title{
Trauma of Hospitalization Is Common in Medical Inpatients But Is Not Associated with Post-Discharge Outcomes
}

\author{
Akshatha Raghuveer, $M D^{7}$, Erik Youngson, MMath², Pamela Mathura, MBA', \\ Narmin Kassam, MD MHPE ${ }^{7}$, and Finlay A. McAlister, MD MSc ${ }^{1,2}$ (D)
}

'Division of General Internal Medicine, Faculty of Medicine and Dentistry, University of Alberta, Edmonton, Alberta, Canada; ${ }^{2}$ Alberta Strategy for Patient Oriented Research Support Unit Data Platform, University of Alberta, Edmonton, Canada.

BACKGROUND: Trauma of hospitalization is characterized by patient-reported disturbances in sleep, mobility, nutrition, and/or mood and one study suggested it was associated with more 30-day readmissions.

OBJECTIVE: To define the trauma of hospitalization in medical inpatients and determine whether higher rates of disturbance correlate with adverse post-discharge outcomes.

DESIGN: A prospective cohort study was conducted between June 2018 and August 2019 with patients reporting disturbances in sleep, mobility, nutrition, and/ or mood. High trauma of hospitalization was defined as disturbance in 3 or 4 domains.

PARTICIPANTS: General medicine inpatients at an academic hospital in Edmonton, Canada.

MAIN MEASURES: 7-day, 30-day, and 90-day rates of death, unplanned hospital readmission, or emergency department (ED) visit.

KEY RESULTS: Of 299 patients (mean age 65.9 years, $47.8 \%$ female, mean Charlson score 3.6, and mean length of stay 8.2 days), 260 (87.0\%) reported disturbance in at least one domain (most commonly nutrition or mobility) during their hospitalization, 179 (59.9\%) reported disturbances in multiple domains, and $87(29.1 \%)$ met the criteria for high trauma of hospitalization. Patients who reported a high trauma of hospitalization did not differ from those reporting less hospitalization disturbances in terms of demographics, burden of comorbidities, or length of stay, but did report higher rates of pre-hospital disturbances in sleep (32.3\% vs. $14.4 \%, p=0.03)$, nutrition (77.4\% vs. $54.4 \%, p=0.02)$, and $\operatorname{mood}(41.9 \%$ vs. $13.3 \%, p=0.0007)$. High trauma of hospitalization was not significantly associated with death, readmission, or ED visit at 7 days (12.6\% vs. $11.3 \%$, aOR 1.13 [95\% CI 0.52-2.46]), 30 days (31.0\% vs. 32.1\%, aOR 1.03 [95\% CI $0.59-1.79]$ ), or 90 days (52.9\% vs. 50.9\%, aOR 1.16 [95\% CI 0.69-1.94]) after discharge. CONCLUSIONS: In-hospital disturbances in sleep, mobility, nutrition, and mood are common in medical inpatients but were not associated with post-discharge outcomes.

Received July 18, 2020

Accepted December 9, 2020

Published online February 5, 2021
KEY WORDS: hospitalization; patient experiences; post-discharge outcomes.

J Gen Intern Med 36(9):2579-84

DOI: $10.1007 / \mathrm{s} 11606-020-06427-4$

(c) Society of General Internal Medicine 2020

$\mathrm{W}$

hile it has long been known that hospitalization exposes patients to risk of iatrogenic illnesses, nosocomial infections, and deconditioning, there is emerging evidence that patient subjective experiences during their hospitalization may also influence their post-discharge outcomes. ${ }^{1-3}$ Detsky and Krumholz described the stressful and depersonalizing effects of the hospital environment as the "trauma of hospitalization" and hypothesized that the cumulative effect of hospital-related disturbances in sleep, mobility, nutrition, and mood (even when not recognized by their care team) may cause physiologic disruptions that worsen patient outcomes, potentially increasing their probability of unplanned readmissions or emergency department (ED) visits. ${ }^{4-6}$

A recently published prospective cohort study used a 10item patient-reported "in-hospital disturbance survey" (see Box 1) to examine the trauma of hospitalization in medical inpatients and post-discharge outcomes. ${ }^{7}$ The survey evaluated the 4 domains of sleep, nutrition, mobility, and mood: the $29.5 \%$ of patients who reported disturbance in 3 or 4 domains in hospital were considered to have high trauma of hospitalization and they exhibited a substantial and statistically significant increase in risk of 30-day readmission or ED visit (37.7\% vs. $21.9 \%$ in those patients who reported lower trauma of hospitalization, adjusted Odds Ratio 2.52 , 95\% CI 1.24 to 5.17). ${ }^{7}$ While this result highlighted a potentially important novel opportunity for future interventions to improve both patient experience and clinical outcomes, their findings must be validated in other settings. Thus, we designed this study to examine the trauma of hospitalization in medical inpatients and to explore whether high scores on the in-hospital disturbance survey are associated with higher rates of readmissions or repeat ED visits or death at 7 days (our primary outcome), 30 days, and 3 months in a different geographic setting. 
Box 1 Disturbance survey (adapted from Rawal et al. ${ }^{7}$ )

\begin{tabular}{|c|c|c|c|}
\hline Domain and Source & Questions & Responses & $\begin{array}{c}\text { Disturbance } \\
\text { Categorization* }\end{array}$ \\
\hline \multicolumn{4}{|c|}{$\begin{array}{l}\text { Same Questions for Baseline and In-Hospital Surveys (Baseline asked "in the } 7 \text { days before this hospitalization" } \\
\text { for each question, In-hospital asked "during this hospitalization") }\end{array}$} \\
\hline Sleep & In the timeframe specified... & & \\
\hline \multirow[t]{4}{*}{$\begin{array}{l}\text { PROMIS Sleep } 4 \mathrm{a} \\
\text { Questionnaire }\end{array}$} & My sleep quality was & $\begin{array}{l}\text { Very poor (5), poor (4), fair (3), good } \\
\text { (2), very good (1). }\end{array}$ & \multirow[t]{4}{*}{$\begin{array}{l}\text { Considered disturbance if } \\
\text { score } \geq 13 \text {. }\end{array}$} \\
\hline & My sleep was refreshing & $\begin{array}{l}\text { Not at all (5), a little bit (4), somewhat } \\
\text { (3), quite a bit (2), very much (1). }\end{array}$ & \\
\hline & I had a problem with my sleep & $\begin{array}{l}\text { Not at all (1), a little bit (2), somewhat } \\
\text { (3), quite a bit (4), very much (5). }\end{array}$ & \\
\hline & I had difficulty falling asleep & $\begin{array}{l}\text { Not at all (1), a little bit (2), somewhat } \\
\text { (3), quite a bit (4), very much (5). }\end{array}$ & \\
\hline \multicolumn{4}{|l|}{ Mobility } \\
\hline $\begin{array}{l}\text { Single Item from Euro-Qol } \\
\text { Five Dimensions } \\
\text { Questionnaire (similar to the } \\
\text { ECOG Performance Status } \\
\text { Score) }\end{array}$ & In the timeframe specified... & $\begin{array}{l}\text { - I had no problems in walking about } \\
\text { - I had slight problems (not fully } \\
\text { active but up and about }>50 \% \text { of } \\
\text { waking hours) } \\
\text { - I had moderate problems (up and } \\
\text { about }<50 \% \text { of waking hours) } \\
\text { - I had severe problems } \\
\text { - I was unable to walk about }\end{array}$ & $\begin{array}{l}\text { Considered disturbance if } \\
\text { moderate or severe } \\
\text { problems in walking about } \\
\text { or unable to walk about. }\end{array}$ \\
\hline \multicolumn{4}{|l|}{ Anxiety/Depression } \\
\hline $\begin{array}{l}\text { Single Item from Euro-Qol } \\
\text { Five Dimensions } \\
\text { Questionnaire }\end{array}$ & In the timeframe specified... & $\begin{array}{l}\text { - I was not anxious or depressed } \\
\text { - I was slightly anxious or depressed } \\
\text { - I was moderately anxious or } \\
\text { depressed } \\
\text { - I was severely anxious or depressed } \\
\text { - I was extremely anxious or } \\
\text { depressed. }\end{array}$ & $\begin{array}{l}\text { Considered disturbance if } \\
\text { moderately to extremely } \\
\text { anxious or depressed. }\end{array}$ \\
\hline \multicolumn{4}{|c|}{ Different Questions for Baseline and In-Hospital Surveys } \\
\hline \multicolumn{4}{|l|}{ Nutrition } \\
\hline \multirow[t]{2}{*}{$\begin{array}{l}\text { Baseline: Canadian } \\
\text { Nutrition Screening Tool }\end{array}$} & $\begin{array}{l}\text { Have you lost weight in the past } 6 \\
\text { months without trying to lose } \\
\text { weight? }\end{array}$ & Yes, No & \multirow[t]{2}{*}{$\begin{array}{l}\text { Considered disturbance if } \\
\text { 'yes' in response to both } \\
\text { questions. }\end{array}$} \\
\hline & $\begin{array}{l}\text { Have you been eating less than } \\
\text { usual for more than a week? }\end{array}$ & Yes, No & \\
\hline \multirow{4}{*}{$\begin{array}{l}\text { In-Hospital: From the } \\
\text { Mealtime and Nutrition Care } \\
\text { Survey }\end{array}$} & $\begin{array}{l}\text { When I was eating, I was } \\
\text { disturbed }\end{array}$ & Yes (1), No (2) & \multirow{4}{*}{$\begin{array}{l}\text { Considered disturbance if } \\
\text { total score }<8, \text { suggesting } \\
\text { that meals were disturbed } \\
\text { or missed in hospital }\end{array}$} \\
\hline & $\begin{array}{l}\text { My mealtimes were interrupted } \\
\text { by staff }\end{array}$ & Yes (1), No (2) & \\
\hline & $\begin{array}{l}\text { I missed meals because I was not } \\
\text { available when they were served }\end{array}$ & Yes (1), No (2) & \\
\hline & $\begin{array}{l}\text { I missed meals because I had to } \\
\text { avoid food for tests }\end{array}$ & Yes (1), No (2) & \\
\hline
\end{tabular}

\section{METHODS}

We conducted a prospective cohort study to collect the inhospital disturbance survey within $24 \mathrm{~h}$ of discharge for adult patients being discharged from general internal medicine wards at the University of Alberta Hospital (an academic tertiary urban hospital with 885 total beds including surgery, pediatrics, and transplant services, but 82 general internal medicine ward beds) after overnight hospital stays between June 2018 and August 2019. We also collected information on the disturbances in each domain the patients reported for the weeks prior to hospitalization for those patients enrolled between November 2018 and August 2019 (baseline disturbances - see Box 1).

We approached all patients being discharged from the general internal medicine wards but excluded those from out of province or those without a valid Alberta Heart Care Insurance number (as we could not track their outcomes), those with moderate to severe cognitive impairment (5 or more errors on the Short Portable Mental Status Questionnaire) or who could not communicate in English, those deemed by their attending physicians to have foreshortened life expectancy or severe 
comorbidities that would preclude 90-day follow-up, or those being transferred to/from another inpatient service (including the intensive care unit), another acute care hospital, or a rehabilitation facility. Patients were included if they were discharged to a long-term care facility if that was their home prior to hospitalization. Our study was approved by the University of Alberta Health Research Ethics Board (Pro00082023) and all potential participants provided written informed consent.

We interrogated the Alberta Health Care Insurance Plan Registry, the Discharge Abstract Database, and the National Ambulatory Care Reporting System to determine the 7-day (our primary outcome), 30-day, and 90-day rates of unplanned hospital readmission, mortality, or ED presentation for each patient to any acute care facility in the province. We also used the linked administrative data to collect socio-demographic variables, medical comorbidities (based on all healthcare encounters in the prior 2 years), and to calculate each patient's LACE index score ${ }^{8}$ at the time of discharge from their index hospitalization. The Pampalon Material Deprivation Index ${ }^{9}$ was used as a proxy for socioeconomic status. This index is derived from census data at the dissemination area (i.e., small geographical area rather than individual level) and includes education level, employment, and income with the end result being quintiles of material deprivation. Additionally, to determine the primary reason for each hospitalization, we used the Episode Diagnosis Category (EDC) which groups similar ICD-10 codes.

Baseline characteristics for the high hospitalization trauma (disturbances in 3 or 4 domains) and low trauma (disturbances in 2 or fewer domains) patients were summarized using means (standard deviations) and counts (proportions) and compared using $p$ values and standardized differences. The association between in-hospital experiences and post-discharge outcomes (death, hospitalization, or ED visit) were evaluated using logistic regression models with the outcomes treated as binary events and adjusting for prognostically important baseline covariates including age, sex, length of stay, and Charlson score (defined as 0,1, or 2+). Of note, the Pampalon Deprivation Index quintiles were not independently associated with post-discharge outcomes in our multivariable model and thus this variable was not included. In a sensitivity analysis, we only adjusted for age, sex, and LACE score (note that we could not include both LACE score and length of stay/Charlson score in the same model since they are highly correlated as the latter two variables are included in the LACE score). In a secondary analysis, we included only the patients who had baseline disturbance data available, with each domain as an additional covariate, and also adjusting for age, sex, length of stay, and Charlson score. $p$ values less than 0.05 were considered to be statistically significant and all analyses were carried out using SAS version 9.4 (Cary, NC, USA) and $\mathrm{R}$ version 3.5.2 (Vienna, Austria).

\section{RESULTS}

Of the 489 patients identified by the treating team as potentially eligible, 23 declined to participate, 76 could not be surveyed prior to discharge (short-term hospitalizations who were discharged before the study team had time to approach them), and 48 were in fact ineligible. Of the 342 patients who consented to participate, 43 were excluded for the reasons listed in Figure 1, leaving 299 patients for our analysis: their mean age was 65.9 years, $47.8 \%$ were female, mean Charlson score was 3.6, and mean length of stay was 8.2 days (Table 1). These 299 patients had 70 different primary (most responsible) diagnoses on their discharge summary (see Appendix eTable 1 for a listing of ICD chapter classifications), but the 5 most common were renal dysfunction $(n=23)$, pneumonia $(n=21)$,

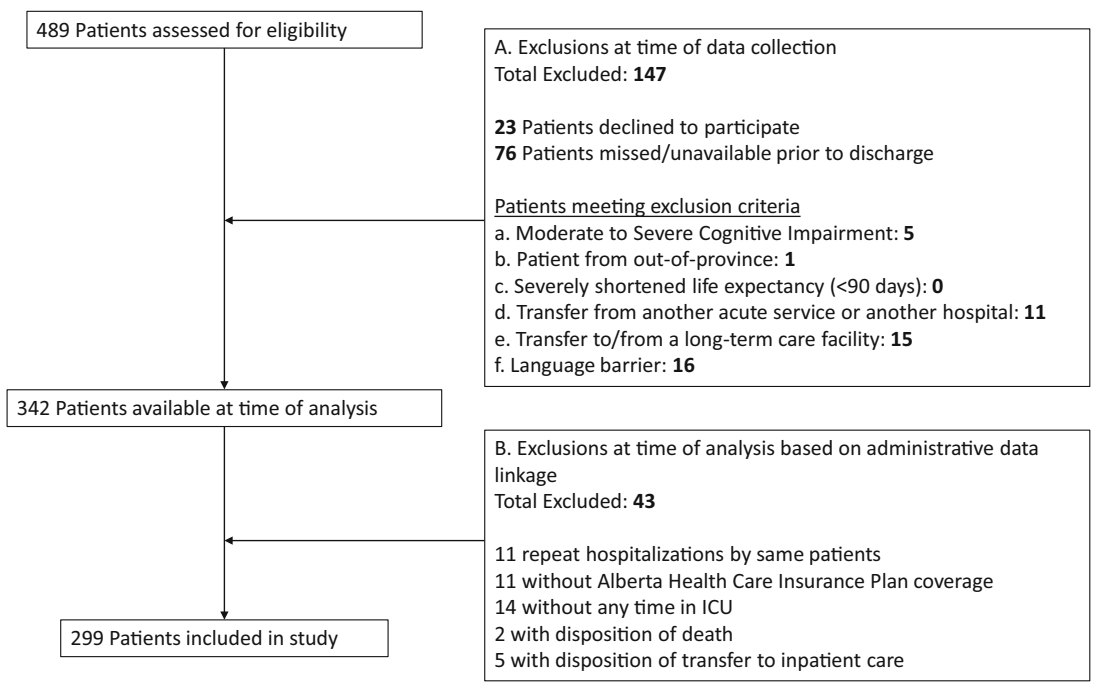

Figure 1 Study flow diagram. 
Table 1 Study Participant Characteristics

\begin{tabular}{|c|c|c|c|c|c|}
\hline Characteristic & $\begin{array}{l}\text { Overall, } \\
N=299\end{array}$ & $\begin{array}{l}\text { Low trauma, } \\
N=212\end{array}$ & $\begin{array}{l}\text { High trauma, } \\
N=87\end{array}$ & $\begin{array}{l}\text { Standardized } \\
\text { difference* }\end{array}$ & $p$ value $*$ \\
\hline Age - mean (SD) & $65.9(18.6)$ & $64.7(18.7)$ & $68.7(18.1)$ & 0.21 & 0.10 \\
\hline Sex female $-N(\%)$ & $143(47.8)$ & $95(44.8)$ & $48(55.2)$ & 0.21 & 0.10 \\
\hline Pampalon Material Deprivation quintile $-N(\%)$ & & & & 0.41 & 0.11 \\
\hline 1 (least deprived) & $67(22.4)$ & $47(22.2)$ & $20(23.0)$ & & \\
\hline 2 & $37(12.4)$ & $23(10.8)$ & $14(16.1)$ & & \\
\hline 3 & $55(18.4)$ & $46(21.7)$ & $9(10.3)$ & & \\
\hline 4 & $49(16.4)$ & $36(17.0)$ & $13(14.9)$ & & \\
\hline 5 (most deprived) & $50(16.7)$ & $36(17.0)$ & $14(16.1)$ & & \\
\hline Missing & $41(13.7)$ & $24(11.3)$ & $17(19.5)$ & & \\
\hline Length of stay-mean days (SD) & $8.2(10.2)$ & $8.0(9.7)$ & $8.9(11.3)$ & 0.09 & 0.46 \\
\hline Charlson Comorbidity Index $-N(\%)$ & & & & 0.11 & 0.60 \\
\hline 0 & $60(20.1)$ & $40(18.9)$ & $20(23.0)$ & & \\
\hline 1 & $24(8.0)$ & $16(7.5)$ & $8(9.2)$ & & \\
\hline $2+$ & $215(71.9)$ & $156(73.6)$ & $59(67.8)$ & & \\
\hline LACE score-mean (SD) & $12.4(3.1)$ & $12.2(3.0)$ & $13.0(3.3)$ & 0.26 & 0.04 \\
\hline \multicolumn{6}{|c|}{ Baseline disturbance (available for 121 patients enrolled between November 2018 and August 2019) } \\
\hline Baseline sleep disturbance & $23(19.0)$ & $13(14.4)$ & $10(32.3)$ & 0.43 & 0.03 \\
\hline Baseline mobility disturbance & $23(19.0)$ & $15(16.7)$ & $8(25.8)$ & 0.22 & 0.26 \\
\hline Baseline nutrition disturbance & $73(60.3)$ & $49(54.4)$ & $24(77.4)$ & 0.49 & 0.02 \\
\hline Baseline mood disturbance & $25(20.7)$ & $12(13.3)$ & $13(41.9)$ & 0.67 & 0.0007 \\
\hline
\end{tabular}

High trauma of hospitalization was defined as disturbances in 3 or 4 domains and low trauma as disturbances in 2 or fewer domains.

*Comparing low trauma with high trauma groups

chronic obstructive pulmonary disease $(n=20)$, heart failure ( $n=17)$, and fluid/electrolyte disturbances $(n=16)$ and there were no statistically significant differences between patients reporting high trauma of hospitalization versus not. As these were all general medical inpatients who had not been transferred between wards, none had undergone surgery during the index hospitalization.

Overall, $260(87.0 \%)$ patients reported disturbance in at least one domain, 179 (59.9\%) reported disturbances in multiple domains, and 87 (29.1\%) fulfilled the criteria for high trauma of hospitalization (Table 1). Sleep was disturbed in 118 $(39.5 \%)$ of medical inpatients, and $176(58.9 \%)$ reported disturbances in nutrition, $162(54.2 \%)$ in mobility, and 100 $(33.4 \%)$ in mood. Patients who reported a high trauma of hospitalization on their surveys did not have any significant differences compared to those reporting lower hospitalization trauma in terms of age $(p=0.10)$, sex $(p=0.10)$, length of stay ( $p=0.45)$, LACE score $(p=0.26)$, or burden of comorbidities $(p=0.60)$. However, those patients reporting high trauma on their in-hospital disturbance survey were also more likely to report having baseline sleep/mood/nutritional disturbances even pre-hospital (Table 1).

Within each domain, death/readmissions/ED visits were not more common at 7, 30, and 90 days in those patients who reported in-hospital disturbance in that domain compared to those who did not (Table 2). Moreover, patients who reported a high trauma of hospitalization did not exhibit significantly higher rates of ED visits, readmissions, or death at 7, 30, and 90 days compared to those reporting less trauma of hospitalization (Table 2), even after adjustment for age, sex, length-ofstay, and Charlson score (aOR 1.13 [95\% CI 0.52-2.46] at 7 days, $1.03[0.59-1.79]$ at 30 days, and $1.16[0.69-1.94]$ at 90 days, eTable 2). In the sensitivity analysis only adjusting for age, sex, and LACE score, there was still no significant association between higher trauma of hospitalization and post-discharge outcomes (aOR 1.10 [95\% CI $0.51-2.38]$ at 7 days, 0.86 [0.49-1.51] at 30 days, and 0.97 [0.57-1.64] at 90 days). If we excluded the 2 patients who died by 7 days, the additional 2 who died between days 8 and 30, and the additional 4 who died between days 31 and 90, there was still no significant association between high hospitalization trauma and readmission/ED visits: aOR 1.28 [95\% CI 0.59-2.82] at 7 days, 1.05 [0.60-1.83] at 30 days, and 1.19 [0.71-1.99] at 90 days. Pre-planned subgroup analyses in patients younger than 65 and 65 or older revealed similar results with no statistically significant association between trauma of hospitalization (nor any specific domain disturbances) and post-discharge outcomes. Including adjustment for baseline disturbances confirmed no significant association between high hospitalization trauma and outcomes: aOR 1.29 [95\% CI 0.29-5.74] at 7 days, $1.95[0.71-5.31]$ at 30 days, and $1.35[0.53-3.47]$ at 90 days (eTable 2 ).

\section{DISCUSSION}

Our study confirmed that disturbances in sleep, nutrition, mobility, and mood are common in hospitalized medical patients. However, disturbances in these domains were also common pre-hospitalization, and those patients reporting more disturbances in hospital (sufficient to meet the literature-based definition of "high trauma of hospitalization") did not exhibit worse post-discharge outcomes than those reporting less in-hospital disturbances.

Thus, despite finding a similarly high rate of disturbances and nearly identical outcome rates at 30 days as reported in the first study of the "in-hospital disturbance survey", 7 we did not find the significant association between trauma of 
hospitalization and 30-day readmission/ED visit rates that they did. We were also able to examine 7-day and 90-day outcome rates, both of which were also not significantly different in those with vs. without self-reported high trauma of hospitalization. Our cohort, like Rawal's, ${ }^{7}$ was drawn from general internal medicine wards in an academic hospital and our patients had similar lengths of stay ( 8.2 vs. 8.0 days) and similar most responsible diagnoses (COPD, pneumonia, and heart failure were 3 of the top 5 in both cohorts). However, the patients in our study were older and had more comorbidities than those in the Rawal study (mean age 65.9 vs. 60.3 years, and $71.9 \%$ of our patients had Charlson scores of 2 or more compared to $30.9 \%$ in the Rawal study), raising the possibility that the impact of in-hospital disturbances may be more important in younger, healthier patients than the older, sicker patients we studied. This theory may be supported by the finding in the Rawal study that patients under 65 years had a greater absolute difference in 30-day readmission between high and low trauma groups (17.9\%) than those 65 and older (8.6\%). One other potentially important difference between the study populations was the substantially higher rates of baseline disturbances in sleep, mood, and mobility reported in the Rawal study (40.6-58.9\% across domains) compared to our study population (19.0-20.7\%).

Although our study is a prospective cohort with objective assessment of outcomes using administrative healthcare records (thereby achieving complete capture of all subsequent events at any acute care facility in the province) collected and analyzed by observers blinded to each patient's in-hospital disturbance score, there are some limitations. First, although frailty is a major driver of post-discharge outcomes, ${ }^{10}$ we did not evaluate patient frailty during hospitalization (although collecting the pre-hospitalization disturbance data is an attempt to mitigate that). Second, our study population was older general medical patients and thus the results may not be generalizable to younger patients admitted to non-medical wards. Third, we do not know which patients were discharged with homecare services in place and any discrepancy in homecare provision could have mitigated outcome differences between the groups. Fourth, and in a similar vein, we do not have data on outpatient follow-up and physician continuity post-discharge, another potential factor mitigating the frequency of readmissions or repeat ED visits. ${ }^{11}$ Fifth, as with any study that relies on patient selfreport of symptoms and domain disturbances, there is always the possibility of recall bias influenced by health status in that sicker individuals may report more disturbances - we attempted to mitigate this by adjusting for comorbidities but cannot remove that possibility entirely. Finally, we did not conduct follow-up assessments to see which patients had persistent disturbances in sleep, nutrition, mobility, and/or mood postdischarge, and we did not examine the relationship between the trauma of hospitalization and post-discharge mental health, functional status, or self-reported well-being of patients, all of which may be more sensitive outcome measures for detecting an impact from hospitalization trauma. 
Although our study did not find significant differences in post-discharge outcomes for patients experiencing high trauma of hospitalization, this does not detract from the fact that disturbances in sleep, nutrition, mobility, and mood are common in hospitalized patients. Improving patient experience is one of the quadruple aims for quality health care, and patientfriendly models of care which attempt to reduce the trauma of hospitalization, particularly in mobility and sleep (such as hospital at home or acute care for elders' units), have shown promising results in reducing length of stay, readmissions, ED visits, and improving patient ratings of the quality of their hospital care. ${ }^{12,13}$ Given the discrepancy between our findings and the earlier observational study ${ }^{7}$ on the trauma of hospitalization, we believe there is a need for further prospective evaluations of this phenomenon and ultimately a multifaceted randomized controlled trial to test whether modifying in-hospital disturbances in sleep, nutrition, mobility, and mood would not only reduce the trauma of hospitalization (i.e., patient experience) but also improve patient outcomes. However, such a trial may well require more sensitive endpoints ${ }^{14}$ than readmission rates, repeat ED visits, or post-discharge mortality.

Supplementary Information The online version contains supplementary material available at https://doi.org/10.1007/s11606-02006427-4

.Acknowledgments: The authors thank the participating patients and the research assistants who collected survey data: Ms. Bernadine Jugdutt, Ms Amanda Lee, Ms Allyson Wrubleski, and Ms. Sophie Collins. We also thank Drs. Amol Verma and Fahad Razak for their comments on an earlier version of this manuscript.

Corresponding Author: Finlay A. McAlister, MD MSc; Division of General Internal Medicine, Faculty of Medicine and Dentistry, University of Alberta, Edmonton, Alberta, Canada (e-mail: Finlay. McAlister@ualberta.ca).

Funding Dr. McAlister holds the Alberta Health Services Chair in Cardiovascular Outcomes Research and this project was supported by the Alberta Health Services Quality Innovation Fund. This study is based in part on data provided by Alberta Health Services through the Alberta Strategy for Patient Oriented Research Data Platform, supported by the Canadian Institutes of Health Research and Alberta Innovates.

\section{Compliance with Ethical Standards:}

Disclaimer: The interpretation and conclusions contained herein are those of the researchers and do not necessarily represent the views of the Government of Alberta nor Alberta Health Services. Neither the Government of Alberta nor Alberta Health Services express any opinion in relation to this study. These organizations were not involved in the design and conduct of the study; collection, management, analysis, and interpretation of the data; preparation, review, or approval of the manuscript; and decision to submit the manuscript for publication.

\section{REFERENCES}

1. Wang DE, Tsugawa Y, Figueroa JF, Jha AK. Association between the centers for medicare and Medicaid services hospital star rating and patient outcomes. JAMA Intern Med 2016;176:848-850.

2. Dong N, Eisenberg JD, Dharmarajan K, Spatz ES, Desai NR. Relationship between patient-reported hospital experience and 30-day mortality and readmission rates for acute myocardial infarction, heart failure, and pneumonia. J Gen Intern Med. 2019;34:526-528.

3. McAlister FA, Lin M, Bakal J, Kemp KA, Guan H. The Care Transitions Measure-3 is only weakly associated with post-discharge outcomes: A retrospective cohort study in 48,384 Albertans. J Gen Intern Med 2019;34:2497-2504.

4. Detsky AS, Krumholz HM. Reducing the Trauma of Hospitalization. JAMA 2014;311:2169.

5. Krumholz HM. Post-Hospital Syndrome - An acquired, transient condition. NEJM 2013;510:100-102.

6. Goldwater DS, Dharmarajan $\mathbf{K}$, McEwen BS, Krumholz HM. Is posthospital syndrome a result of hospitalization-induced allostatic overload? J Hosp Med 2018;13: https://doi.org/10.12788/jhm.2986

7. Rawal S, Kwan JL, Razak F, Detsky AS, Guo Y, Lapointe-Shaw L, Tang T, Weinerman A, Laupacis A, Subramanian SV, Verma AA. Association of the 'trauma of hospitalization' with 30-day readmission or emergency department visit. JAMA Intern Med 2019;179:38-45.

8. van Walraven C, Dhalla IA, Bell C, Etchelles E, Stiell, IG, Zarnke, K. et al. Derivation and validation of an index to predict early death or unplanned readmission after discharge from hospital to the community. CMAJ 2010;182:551-557.

9. Pampalon R, Hamel D, Gamache P. Health inequalities in urban and rural Canada: comparing inequalities in survival according to an individual and area-based deprivation index. Health Place. 2010;16(2):416-420.

10. Kahlon S, Pederson JL, Majumdar SR, Belga S, Lau D, Fradette M, Boyko D, Bakal J, Johnson C, Padwal RS, McAlister FA. Association between frailty and 30-day outcomes after discharge from hospital. CMAJ 2015; 187:799-804.

11. Pereira Gray DJ, Sidaway-Lee K, White E, et al. Continuity of care with doctors - A matter of life and death? A systematic review of continuity of care and mortality. BMJ Open 2018;8:e021161

12. Federman AD, Soones T, DeCherrie LV, et al. Association of a bundled hospital-at-home and 30-day postacute transitional care program with clinical outcomes and patient experiences. JAMA Intern Med 2018; 178: 1033-1040.

13. Fox MT, Persaud M, Maimets I, et al. Effectiveness of acute geriatric unit care using acute care for elders componenets: a systematic review and meta-analysis. J Am Geriatr Soc 2012;60:2237-2245.

14. Brown $\mathbf{C J}$. A focus on patient-centered care required to address the trauma of hospitalization. JAMA Intern Med 2019;179:46-47.

Publisher's Note Springer Nature remains neutral with regard to jurisdictional claims in published maps and institutional affiliations. 